\title{
Entre crenças e aparências: compreensões sobre ciência por licenciandos em ciências da natureza
}

Eril Medeiros da Fonseca erilmf@gmail.com 0000-0001-9529-2357 Universidade Federal do Pampa, Dom Pedrito, Rio Grande do Sul, Brasil.

Leandro Duso

dusoleandro@gmail.com

0000-0002-2605-0829

Universidade Federal do Pampa,

Dom Pedrito, Rio Grande do Sul,

Brasil.

\section{RESUMO}

O presente artigo investigou e discutiu as concepções de licenciandos de um curso de Ciências da Natureza em relação à Natureza da Ciência e o perfil do cientista no fazer científico, no âmbito de um componente curricular de experimentação no ensino de ciências. Possui caráter qualitativo, em que os dados foram coletados por meio da aplicação de um questionário e pela construção de um diário de aula, que contribuiu na compreensão do discurso dos sujeitos da pesquisa. Através da Análise de Conteúdo sistematizaram-se os resultados em duas categorias, das quais: visão deformada sobre a natureza da Ciência e imagem reducionista do cientista. Os resultados apontaram uma compreensão acrítica sobre a Ciência, pautada por uma visão salvacionista, reducionista e utilitarista do trabalho científico, indicando a necessidade de se discutir e repensar a abordagem de tais questões e o modo como são abordadas na formação de professores.

PALAVRAS-CHAVE: Natureza da ciência. Fazer científico. Ensino de ciências. 


\section{INTRODUÇÃO}

A configuração da Ciência e sua produção é consequência de uma tendência positivista, relacionada a uma racionalidade científica, um modelo totalitário, que não considerava as ideias de sendo comum, pautada pela quantificação do conhecimento, culminando na redução da complexidade do mundo, prevalecendo à ordem e a previsibilidade.

A Ciência acadêmica, privilegiando a ilustração, verificação e memorização de um corpo de conhecimentos perfeitamente estabelecido, não controverso, apresenta a Ciência como um processo objetivo, isento de valores, que conduz a verdades absolutas, inquestionáveis, através da observação rigorosa de regularidades nos fenômenos e do estabelecimento de generalizações.

Embora a Ciência tenha ganhado rigor e autonomia, acarretou no desinteresse do conhecimento, na proletarização, divisão dos centros de investigação e no domínio do desenvolvimento científico por poucos (SANTOS, 2006).

Santos (2006) menciona que a produção de conhecimento pela Ciência deve ser intensificada pelo diálogo entre saber científico e senso comum, sabendo que a Ciência não é um conhecimento restrito apenas ao espaço acadêmico, mas faz parte de uma instância maior, social, que pelos meios de comunicação torna-se mais ampla, influenciando decisões éticas, políticas e econômicas.

Delizoicov, Angotti e Pernambuco (2011, p. 23) definem Ciência como "um conteúdo cultural relevante para viver, compreender e atuar no mundo contemporâneo", engendrados com métodos e atividades comprometidas com um trabalho coletivo entre professores e alunos, tanto na academia/escola como na sociedade, permitindo tratar o conhecimento de forma ampla, não dicotomizando teoria e prática.

Na opinião de Cachapuz et al. (2000), o grande objetivo da aprendizagem em Ciência deverá consistir na familiarização do aluno com as características do trabalho científico, ajudando-o a compreender os seus percursos, bem como as suas múltiplas facetas, colocando-o numa situação de cidadão ativo, apto a decidir em situações pluridisciplinares, nas quais a Ciência é uma entre as várias vozes da sociedade. Freire Jr. (2003) está convicto de que o desenvolvimento de uma imagem mais realista e multifacetada da Ciência poderá contribuir para a melhoria da relação entre a Ciência e a sociedade, representando o melhor antídoto contra tendências irracionalistas contemporâneas.

Harres (2003) menciona que embora os currículos de Ciência variem na direção de diferentes contextos, buscando atender a demandas emergentes, a visão historicamente marcada sobre a Ciência é refletida por uma distinção entre epistemologia e a própria natureza da Ciência ( $\mathrm{NdC}$ ).

As visões sobre os currículos de Ciência comumente empregadas referem-se a uma tradição empirista, que consideram o caráter teórico e observacional da Ciência de forma fragmentada, onde o conhecimento é visto de modo fechado, apartado da ação do mundo (HARRES, 2003). Essas visões refletem na ação docente sobre o que ensinar e como ensinar.

Nesta mesma perspectiva, Gil-Perez et al. (2001), descrevem sete visões deformadas dos professores em relação ao trabalho científico, destacamos 
algumas que julgamos serem relevantes no saber-fazer científico, das quais: visão rígida; visão aproblemática e ahistórica e visão individualista e elitista da Ciência.

A visão rígida apresenta o método científico como um conjunto de etapas seguido de forma mecânica e exata, evitando qualquer tipo de criatividade e/ou ambiguidade. A visão aproblemática e ahistórica caracteriza-se por uma perspectiva fechada e sem relações históricas da produção científica e epistemológica. A compreensão do conhecimento dá-se de modo pontual, desconsiderando as referências anteriores que o produziram.

$\mathrm{Na}$ visão individualista e eletista os conhecimentos científicos são descritos como obras acabadas de "gênios" que concluíram seus resultados de modo particular, sem inter-relações a outros sujeitos ou hipóteses. Do mesmo modo, tal conhecimento é reservado a uma mínima parcela, eminentemente masculina e na maioria das vezes acessível a poucos.

Estas visões deformadas da Ciência não são de estranhar, pois a maior parte dos professores raramente teve contato com a atividade científica ou oportunidade de refletir e de aprender sobre o funcionamento da Ciência. Em vários países, os cursos de formação inicial de professores não valorizam nem proporcionam os conhecimentos necessários ao ensino da $\mathrm{NdC}$, pois centram-se na aquisição dos produtos intelectuais da Ciência e ignoram o processo de produção de conhecimento (GALLAGHER, 1991).

Diante do exposto Chassot (2003a; 2003b) menciona que há uma predominância da presença masculina na área da Ciência, na qual tem sua origem europeia, de modo que a própria História da Ciência está intensamente ligada a História da Humanidade e não pode ser vista sem as diferentes conexões existentes entre ambas.

Diante do exposto, acreditamos que a Ciência e a própria produção científica caracterizam-se como uma atividade humana, com interdependências entre sujeitos e contextos, portanto, não neutra, com intencionalidades e influenciada por fatos, fenômenos e relações sócio-históricas.

Logo, os professores tendem a sub-valorizar a $\mathrm{NdC}$ na sua prática de ensino (LAKIN; WELLINGTON, 1994), limitando-se a transpor os modelos de trabalho dos seus formadores, marcados pelo domínio da dimensão pedagógica e pela desvalorização ou inexistência de reflexão epistemológica consciente (CACHAPUZ et al., 2000; PRAIA; CACHAPUZ, 1998).

Nesta perspectiva, o presente artigo destina-se a analisar e discutir as concepções de licenciandos de um curso de Ciências da Natureza sobre a NdC.

\section{CONCEPÇÕES DE CIÊNCIA E SUAS IMPLICAÇÕES NO ENSINO DE CIÊNCIAS}

Fonseca (2002, p. 11) define Ciência como "[...] o saber produzido através do raciocínio lógico associado à experimentação prática. Caracteriza-se por um conjunto de modelos de observação, identificação, descrição, investigação experimental e explanação teórica de fenômenos". Considera-se, portanto, que a Ciência é mais uma das formas de compreender o mundo e as transformações que nele ocorrem, gerando conhecimentos que tornem os sujeitos aptos a interagir com tais transformações, intervindo em sua realidade. 
Por definição Ciência é um conjunto de conhecimentos socialmente adquiridos ou produzidos e historicamente acumulados, constituídos de uma objetividade que permite sua transmissão, estruturada com métodos, teorias e linguagens próprias, visando compreender e orientar a natureza e as atividades humanas (FERREIRA, 1986).

Borges (2007) na obra Em debate: cientificidade e Educação em Ciências, sistematiza algumas visões sobre a Ciência, consideradas ao longo do tempo, por diversos teóricos, descritas a seguir.

Lakatos descreve uma visão tradicional da Ciência, pautada pelo método científico empirista-indutivista, a partir de observações e formulação de teorias, possui um critério único, atemporal, não histórico e universal. Segundo Lakatos e Musgrave (1979, p.217) dentro de um programa de pesquisa deve-se "[...] infalivelmente planejar suas teorias auxiliares na esteira dos fatos, sem antecipar outros".

Para Popper a Ciência evolui através de refutações, pois nunca se pode provar que algo é totalmente verdadeiro, demonstrando que algumas ideias são falsas. A partir disso obtém-se uma nova teoria e se aperfeiçoa outra (BORGES, 2007).

A visão contextualista de Kuhn considera que o conhecimento depende do que é importante ou do que é valorizado por alguém ou comunidade, é conservado, resistindo a mudanças. Na visão do "anarquismo metodológico" de Feyerabend não existe uma regra metodológica rígida de pesquisa, pois toda regra de pesquisa já foi violada, sendo necessária para o progresso (BORGES, 2007).

Bachelard, na visão dialética, vê o conhecimento científico como racionalista e realista, pois toda observação/experimentação antecede uma teoria, rompendo o diálogo entre conhecimento científico e senso comum, desconfiando de resultados imediatos (BORGES, 2007).

Bachelard (1996) também considera dentre outros obstáculos à superação da natureza verbal, nela uma única imagem ou palavra constitui a explicação para um fenômeno da natureza, através de metáforas. Segundo o autor a atribuição de imagens para explicar determinados fatos e/ou fenômenos podem suprimir a necessidade de explicação, deixando tudo muito simples, seria a criação de esquemas gerais, que reprimem maiores aprofundamentos, prejudicando a razão, impedindo a visão abstrata e a evolução do pensamento.

A visão externalista da Ciência, abordada também por Bunge, considera as influências externas dadas ao conhecimento. Nessa visão as temáticas da produção científica não atendem apenas aos interesses de uma comunidade científica, mas dialogam com fatores sociopolíticos, econômicos e culturais.

Além disso, frequentemente, a mídia transmite uma imagem distorcida da Ciência e ideias estereotipadas acerca dos cientistas e da sua atividade, com um impacto considerável nas concepções e na confiança do público acerca dos empreendimentos científicos e tecnológicos (NELKIN, 1995). Segundo Nelkin (1995) a investigação científica é muitas vezes apresentada aos estudantes e a sociedade, como uma atividade esotérica, misteriosa e extremamente complexa, cuja compreensão e prática só está ao alcance de um número restrito de iluminados que vivem completamente isolados e absorvidos pelo seu trabalho. 
Assim, de acordo com Harres (1999, p. 198), "as concepções sobre a NdC inadequadas dos estudantes mais comuns encontradas incluem, entre outros aspectos", os seguintes:

- a consideração do conhecimento científico como absoluto;

- a ideia de que o principal objetivo dos cientistas é descobrir leis naturais e verdades;

- lacunas para entender o papel da criatividade na produção do conhecimento;

- lacunas para entender o papel das teorias e sua relação com a pesquisa;

- incompreensão da relação entre experiências, modelos e teorias.

Consequentemente, as visões postas ao Ensino de Ciências refletem algumas concepções descritas acima, que foram hegemônicas, ditando conceitos e regras pré-estabelecidas de compreender a definição de Ciência e quem a produz. 0 processo de aprendizagem era vinculado a aspectos apenas técnicos, colocando o estudante como sujeito passivo, desvinculado de valores pessoais e profissionais.

Na década de 60 e 70, no Ensino de Ciências, buscava-se pensar de forma lógica e crítica, vivenciando o método científico com discussões de pesquisas realizadas no laboratório. Ao invés de se considerar o produto, passava-se a considerar o processo (KRASILCHIK, 1987).

Assim, constituiu-se duas visões em relação à Ciência: uma defendia a ideia de que a mesma ajudaria na resolução de problemas cotidianos, e a outra visava à formação acadêmica, que previa a formação de cientistas. Esta última prevaleceu de maneira formal, baseada em definições, deduções e equações, trabalhando com experimentos em que os resultados são pré-estabelecidos (KONDER, 1998).

Esta concepção é reafirmada pelo desenvolvimento industrial, admitindo a Ciência e a tecnologia como aspectos essenciais na economia brasileira. Levando a criação de unidades escolares em áreas como Física, Química e Geologia, preparando indivíduos para ensinar tais áreas. A Biologia surge posteriormente por trabalhar com conceitos mais complexos (KONDER, 1998).

A preocupação em constituir áreas específicas do saber estritamente para a profissionalização, contribuiu para a fragmentação no Ensino de Ciências, afetando o currículo das instituições de ensino.

$\mathrm{Na}$ década de 80, visava-se, no Ensino de Ciências, analisar implicações sociais no desenvolvimento científico e tecnológico. A tendência era trabalhar com resolução de problemas, através de jogos e simulações, realizando articulações com Centros de Ciências e universidades (KRASILCHIK, 1987).

Diante do exposto, percebeu-se a necessidade de um ambiente que se oponha a essa concepção tecnocrática de ensino, demandando uma discussão de cunho democrático. Desta forma, o Ensino de Ciências caracteriza-se como uma possibilidade de desenvolver um conhecimento que vá além de conceitos e ideias, da cultura científica, de modo que os estudantes percebam os fenômenos da natureza e com isso estejam aptos a elaborar hipóteses, concepções e organizar ideias, preparando-os para agirem fora do ambiente escolar (CARVALHO, 2011). 
O Ensino de Ciências é definido segundo Chassot (2011), como uma linguagem para possibilitar uma leitura do mundo. Esta leitura possibilita uma apropriação de conceitos científicos, ampliando a dimensão de conhecimentos essenciais para a formação de uma postura em relação ao ambiente em que se vive.

Segundo Marco (1999, p. 95)

formar cidadãos cientificamente cultos não significa dotá-los de uma linguagem científica, e sim ensinar a desmistificar e decodificar as crenças aderidas a Ciência e aos cientistas, abstrair de sua aparente neutralidade, entrar nas questões epistemológicas e nas terríveis desigualdades ocasionadas pelo mal uso da Ciência e suas condições sócio-políticas.

Com isso, a apropriação de conhecimentos científicos deixaria de atender a necessidades relacionadas somente aos interesses políticos, econômicos, profissionais e/ou pessoais, para desenvolver a compreensão concreta de conceitos que componham e auxiliem no entendimento da conjuntura da realidade local, desencadeando assim um processo que contemple a cultura vivida.

Harres (2003) afirma que algumas características em relação ao Ensino de Ciências evidenciam uma concepção deturpada que se criou sobre a mesma, pautada por um vocabulário técnico, com memorização de fatos e domínio de fórmulas, em uma perspectiva individual e não-social. $O$ autor menciona que as consequências dessa visão para o ensino são bastante evidentes, materializadas na transmissão de conhecimento de forma acabada e não dinâmica, aplicação do método científico de forma acrítica e desconsideração do caráter evolutivo, especulativo e humano do conhecimento científico.

Auler e Delizoicov (2006) buscando perceber as compreensões de professores e futuros professores de Ciências sobre interações entre a Ciência, a Tecnologia e a Sociedade, descrevem a passividade diante do desenvolvimento científico, necessitando a superação da perspectiva salvacionista atribuída a Ciência. Em relação aos cientistas, mencionam que, de modo geral, são considerados pessoas objetivas, imparciais, possuidoras de verdade e por vezes loucas lutando pelo bem da humanidade.

Krasilchik (1987) aponta que as Ciências têm sido ensinadas como uma coleção de fatos e descrições de fenômenos, sem relações com mecanismos históricos. A percepção apática e fechada de Ciência culmina com as limitações das aulas de Ciências, o que faz com que o componente curricular do mesmo se torne irrelevante e sem significado. Portanto, mesmo com a diversidade de diferenças sociais, culturais, econômicas e regionais que uma instituição de ensino abarca, origina-se, cada vez mais, um distanciamento entre o que se ensina, o que se vive e o que se faz, limitando o rendimento do ensino.

\section{METODOLOGIA E CONTEXTO DA PESQUISA}

Os sujeitos da pesquisa foram vinte e dois (22) licenciandos do terceiro semestre do componente curricular de Práticas pedagógicas: experimentação no Universidade Federal do Pampa - Campus Dom Pedrito/RS. 
O curso visa formar profissionais que compreendam a realidade social, na qual se insere a escola em que atua, estimulando a curiosidade científica com seus educandos, de modo que reflita eticamente perante a sociedade e natureza. Possui caráter interdisciplinar e seus acadêmicos estão aptos a atuarem nos anos finais do Ensino Fundamental e Ensino Médio (UNIPAMPA, 2015).

O componente curricular Práticas pedagógicas: experimentação no Ensino de Ciências visa discutir os modelos atuais de Ensino de Ciências: transmissão/recepção; redescoberta e mudança conceitual; aprendizagem significativa e novas possibilidades no ensino e aprendizagem em Ciências. Como objetivo, pretende: Compreender a abordagem epistemológica da história da experimentação no Ensino de Ciências, com ênfase na análise do valor pedagógico e da contribuição no processo e aprendizagem do Ensino de Ciências Naturais na perspectiva do Ensino Básico (UNIPAMPA, 2015).

Optamos por trabalhar com a concepção da $\mathrm{NdC}$ e a visão que os licenciandos têm dos cientistas, por ser uma questão anterior à discussão sobre experimentação que se propõe o componente curricular, já que a visão sobre Ciência que cada um possui, baliza as práticas e concepções em relação ao Ensino de Ciências e a própria experimentação.

A coleta dos dados baseou-se na aplicação de um questionário, no início do componente, com questões abertas, que versavam sobre a compreensão da $\mathrm{NdC}$ e o perfil físico e social de um cientista. As questões buscavam compreender a concepção dos licenciandos em relação à Ciência, quem é considerado um cientista e que atividades o mesmo desenvolve.

Durante as aulas foram realizadas anotações em um diário de aula (ZABALZA, 2004) das falas dos licenciandos que teve como objetivo verificar a mudança do discurso em relação às concepções de Ciência e fazer científico. Algumas considerações sobre o que havia sido discutido eram anotadas no diário após cada aula, bem como possíveis avanços ou limitações relacionadas ao entendimento de cada licenciando.

A turma era composta por vinte e oito (28) estudantes, porém no decorrer do componente houve desistência de seis (06), portanto, restaram vinte e dois (22) licenciandos que participaram integralmente do componente. Vale ressaltar que a participação na pesquisa teve o consentimento de todos os envolvidos.

Uma vez organizados os dados coletados, passamos a tratá-los por meio da Análise de Conteúdo (BARDIN, 2009), que consiste em três etapas. Na primeira, Pré-análise, fase de sistematização das ideias para criação de um plano de análise, ocorreu a leitura atenta dos questionários e registros feitos no diário de aula. Na segunda etapa, Exploração do material, realizou-se a codificação, enumerando as falas dos licenciandos para a criação de possíveis categorias. Já na terceira etapa, Tratamento dos resultados obtidos e interpretação, foi feito a síntese dos resultados, confrontando-os com as dimensões teóricas.

Para organizar o conjunto dos fragmentos referentes às falas dos licenciandos foi adotada a sistemática de grafá-las com a letra "L". Estes foram numerados de 1 a 22 sem que a numeração guarde qualquer relação com o respondente. Tais fragmentos aparecem grafados em itálico e entre aspas no texto. 


\section{DISCUTINDO OS RESULTADOS}

A utilização dos fragmentos das falas dos licenciandos possibilitou aprofundar a discussão de alguns elementos, que foram sistematizados nas seguintes categorias: visão deformada sobre a $\mathrm{NdC}$ e imagem reducionista do cientista. É importante mencionar que as respostas dos licenciandos foram mantidas na íntegra, pois não foram feitas correções gramaticais ou mudanças em relação à língua portuguesa.

\section{Visão deformada sobre a NdC}

Neste item discutimos as visões dos licenciandos em relação à $\mathrm{NdC}$ e ao fazer científico, modos e meios de produção. As compreensões envolvem uma variedade de atribuições sobre Ciência que em um dado momento integram as concepções sobre o Ensino de Ciências. Entendemos que tais visões são influenciadas por diferentes segmentos sociais (meios de comunicação, vivência familiar, ambiente escolar, tipo de formação inicial) que contribuem para reforçar o entendimento que cada um possui sobre Ciência e o seu fazer.

A partir das respostas dos questionários dadas pelos licenciandos percebeuse que alguns acadêmicos descreveram a Ciência de forma naturalista, relacionando com o estudo dos fenômenos naturais, seres vivos e fatos cotidianos, demonstrando uma relação entre Ciência e questões ambientais, exemplificadas pelas respostas do L9 e L2, respectivamente: "estudo dos fenômenos naturais, físicos e químicos de extrema importância para o esclarecimento dos fatos do cotidiano" e "estudo de todos os seres vivos no meio ambiente".

Essas visões aproximam-se do chamado naturalismo ontológico, mencionado por Silveira (2014), pois a natureza é tudo que existe a respeito do que compõem a realidade e a Ciência estaria diretamente relacionada a questões naturais, por estudar esses fenômenos.

Segundo Kosminsky e Giordan (2002) essa visão é corroborada pelos veículos de comunicação e divulgação científica, pois desempenham uma contribuição determinante para moldar as visões de Ciências, exercendo uma influência devido à difusão pelas estruturas sociais.

Percebemos no discurso do L9 uma mudança em sua concepção naturalista para uma visão mais sistêmica, "Ciência é todo conhecimento adquirido através do estudo ou da prática, de qualquer área do conhecimento". O mesmo percebemos na resposta do L2: "Engloba todo conhecimento adquirido, estudos e nos explica os acontecimentos".

Esse naturalismo também foi identificado através da descrição do L3, porém identificamos alguns elementos que se aproximam das ideias de Popper quando menciona que a Ciência é o "conhecimento que é adquirido através de estudos e práticas, baseados em reflexões e ideias que podem ser abandonadas, renovadas ou criadas novas".

Percebemos o movimento dinâmico, não estanque, que o discente agrega a Ciência, que se harmoniza com as proposições de Popper considerando a substituição do método científico tradicional pelo método científico hipotético- 
dedutivo. Nessa perspectiva hipóteses são elaboradas e reformuladas, possibilitando um aperfeiçoamento das teorias e o avanço do conhecimento (BORGES, 2007).

O L2 e L4 também mencionaram que as atividades realizadas pelos cientistas são vinculadas a realização de experimentos e práticas observacionais, a saber: "Experimentos, pesquisas e descobertas, atividade de pesquisa e práticas" (L2). "Experimentação, práticas sobre algo científico e observações". “Experimentação, observação" (L4).

Nessa visão a Ciência associada à experimentação cresce por sucessivas conjecturas e refutações. Uma teoria científica é refutada por experimentos que podem a contradizer (BUENO, 2015), demonstrando a construção histórica atribuída ao fazer científico e a ideia de admitir a produção científica pelo seu próprio caráter humano.

$\mathrm{Na}$ reinterpretação de Lakatos (1979) ao falseacionismo de Popper, as teorias não são refutadas por experimentos, mas através de outras teorias, a partir de programas de pesquisa, o que difere das afirmações de L27 sobre Ciência: "Conhecimento adquirido através de experimentos, estudos e hipóteses".

Lakatos propõe que o progresso científico é encaminhado, pelo que denomina de programas de pesquisa, que seriam diretrizes metodológicas correspondentes a construção e modificação de teorias. A partir dos programas as teorias desenvolvem-se e sobrevivem a possíveis refutações, e a competição entre elas é uma característica do processo do desenvolvimento científico, que são resguardadas/garantidas em cinturões protetores (LABURÚ; ARRUDA; NARDI, 1998).

Nesse sentido, "as teorias não são elementos isolados, mas pertencentes a um determinado programa" (LABURÚ; ARRUDA; NARDI, 1998, p. 4), e qualquer fenômeno que destoa das ideias defendidas tornam-se um desafio a ser explicado dentro de um programa.

Através dos programas de pesquisa as teorias tendem a evoluírem e permanecerem, enquanto outras incapazes de ofertar soluções satisfatórias a determinados problemas investigados acabam desaparecendo (BORGES, 2007).

Já na fala de L20, percebemos uma visão mais conteudista relacionada ao Ensino de Ciências, a saber: "Tem como objetivo passar as matérias de Biologia que estuda a vida, Química que estuda as formas e o porquê delas, e a Física que estuda o que seria movimentos". "É a matéria que abrange vários temas que ocorrem no nosso dia a dia, com conteúdos que abrangem os conteúdos de Física, Química e Biologia". Essa visão provavelmente teve influência de uma ideia clássica de Ciência, herdada de um paradigma cartesiano, pautado no determinismo, racionalismo e mecanicismo (LAURINO; PINTO; NOVELLO, 2013).

Nessa concepção, segundo Laurino, Pinto e Novello (2013, p. 2) o cientista é aquele que descobre algo que já está posto, objetivo, sem considerar sua subjetividade. Essa visão influencia também as concepções de práticas educacionais, pois pressupõem representações científicas já construídas, que acabam apenas sendo transmitidas como verdades aos estudantes. 
Nesse sentido, aceitar/acreditar em uma única verdade independente das ações humanas é negar o potencial criativo e investigativo do estudante, e para tal, negar a responsabilidade de cada um sobre o mundo. Por isso, os objetivos do Ensino de Ciências deveriam ser de educar cientificamente a população para que tenham consciência dos problemas do mundo e de sua possibilidade de atuação sobre os mesmos, de sua capacidade de modificar situações, incluso as amplamente aceitas.

O L15 e L22, respectivamente, atribuíram uma visão salvacionista ao papel do cientista: "Desenvolvem pesquisas, procuram descobertas na área de saúde, procuram cura, através de remédios e vacinas para alimentação, pesquisam melhorias que não afetem tanto no ser humano, no meio ambiente, sempre à procura de mantê-lo habitável e sustentável". "Pesquisa de grande e profunda importância, sobre doenças, remédios, sobre o meio em que vivemos".

Percebemos o papel redentor associado à Ciência, em que as atividades realizadas são relacionadas à busca de soluções a problemáticas como saúde pública e equilíbrio ambiental, atribuindo uma posição neutra no fazer científico, e de certo modo desconsiderando influências e intencionalidades políticas, sociais e econômicas.

Delizoicov e Auler (2011, p. 251) consideram que na produção científica devem-se levar em conta alguns parâmetros como "investimento financeiro para a pesquisa científico-tecnológica e interesses estratégicos, das nações e governos, ao planejarem e promoverem seus projetos de pesquisa e desenvolvimento (P\&D)".

Assim, os problemas científicos assumem uma dimensão não apenas temporal, mas espaço-temporal, pois demonstram uma intencionalidade através de sua localização e formulação (DELIZOICOV; AULER, 2011), pressupostos que contribuem para compreender o caráter não-neutro da gênese da Ciência e do próprio sistema científico-tecnológico.

A compreensão de uma Ciência neutra ainda permanece fortemente presente em vários âmbitos da sociedade, em instituições como a academia e laboratórios de pesquisa e, conforme detectado por Gil Perez et al. (2001), além dos meios de comunicação, também parece estar presente em alguns setores da Universidade, na sociedade em geral e na Educação em Ciências.

Para Oliveira (2008), assumir a neutralidade da ciência, isolando-a da esfera valorativa, significa uma Ciência fora do alcance de questionamentos em termos de valores sociais, dimensão esta impregnada na cultura ocidental.

Auler (2002) identifica e analisa quatro dimensões interdependentes sobre a não neutralidade da Ciência e Tecnologia, sendo elas: 1) O direcionamento dado à atividade científico tecnológica (processo) resulta de decisões políticas; 2) A apropriação do conhecimento científico-tecnológico (produto) também resulta de decisões políticas; 3) O conhecimento científico produzido (produto) não é resultado apenas dos tradicionais fatores epistêmicos: lógica + experiência e 4) O aparato ou produto científico-tecnológico incorpora, materializa interesses, desejos de sociedade ou de grupos sociais hegemônicos.

Diante disso, as atividades de pesquisa deveriam ser direcionadas pela formulação dos problemas significativos para um determinado grupo e cuja solução é buscada pelos conhecimentos e práticas por ele compartilhados 
(DELIZOICOV, 2004). Deste modo, a caracterização da não-neutralidade, deve ser direcionada aos problemas a serem investigados pela área de Ensino de Ciências, no Brasil.

Dentre as várias possibilidades de se enfrentar o desafio dessa busca de sintonia, não se pode deixar de mencionar a contribuição que Freire (2016) dá através da proposição da investigação temática. Através dela, segundo argumenta esse educador, a equipe de pesquisadores pode identificar, em um processo dialógico e participativo, as temáticas significativas que são próprias de uma unidade epocal (FREIRE, 2016), ou seja, de características historicamente situadas, e que são manifestações locais de contradições sociais mais amplas, conforme também argumenta Santos (1977).

Nesse sentido, convém mencionar, assim como assinala Carvalho (2012), que para fazer, falar, ler e escrever Ciência é necessário combinar de muitas maneiras o discurso verbal, as expressões matemáticas e representações gráficas. Nesse cenário, as linguagens falada e escrita são sistemas simbólicos que são utilizados para elaborar, descrever e apresentar processos e construir argumentos científicos. Segundo a autora, tais habilidades e competências deveriam ser suscitadas no ensino de Ciências desde os primeiros anos do Ensino Fundamental, de modo a desenvolver uma linguagem comum, do cotidiano a uma linguagem científica, utilizando de ferramentas científicas.

Além do caráter não neutro identificamos também a visão utilitarista vinculada a Ciência e Tecnologia, remetendo a ideia de que essas instâncias trarão a cura a doenças e "descobrirão" medicamentos, tendo como princípio balizador a preservação da vida, atribuída como um "bem comum" a todos.

Essas visões são descritas por L14 "descobertas de medicamentos para cura de doenças". O mesmo percebemos do L16, quando menciona: "criação de medicamentos para proteger a vida", e ajudar pessoas, no caso de tecnologias, nanotecnologias, medicamentos".

O entendimento de L19 relaciona-se ao desenvolvimento científicotecnológico, pois engloba vários temas, com objetivos diferenciados, como estudo da natureza e produção de remédios, assim menciona que Ciência "é o que estuda o porquê das coisas, buscando sempre uma real explicação dos acontecimentos pensando sempre na evolução". O L25 também considera: "Estudo dos fenômenos naturais e tecnológicos, graças a ela não vivemos na época da pedra".

Percebemos o caráter utilitarista que os acadêmicos atribuem a Ciência, já que uma característica marcante na fala dos mesmos é a finalidade que o desenvolvimento científico possui: servir para. Nesta perspectiva, Bachelard (1996) caracteriza um aspecto marcante do pensamento pré-científico, a ideia de que todo fenômeno, necessariamente, precisa ter uma utilidade para ser validado, pois se não ganhar uma característica particular parece que não foi explicado. Esses aspectos constituem o obstáculo a ser superado do conhecimento unitário e pragmático.

Essa concepção, comumente aceita, transmite uma imagem deformada, descontextualizada e ingênua sobre o desenvolvimento científico. Os cientistas passam a ser considerados como seres "acima do bem e do mal", fechados em torres de marfim, que proporcionam soluções a problemáticas de cada 
sociedade/tempo (GIL-PEREZ et al., 2001). Nesse pensamento a Ciência não deveria servir "para", mas partir de um "desejo", um "querer", já que para Bachelard (1996) é considerada como uma linguagem própria, específica, com conceitos próprios.

Essa visão utilitarista, segundo Auler e Delizoicov (2006) é bastante difundida, já que se tem a ideia de que em algum momento, do presente ou futuro, Ciência e Tecnologia irão "resolver" os problemas existentes, propiciando um bem-estar social. Tanto Ciência como Tecnologia são associadas como redentoras, ignorando-se as relações sociais em que ambas estão inseridas.

Porém, é relevante mencionar que na medida em que a Ciência penetrou na indústria, esta "foi profundamente industrializada" (JAPIASSU, 1988, p. 146). Em sua análise, Japiassu considera que isto não quer dizer que os fins meramente utilitários predominem na orientação da Ciência, mas que as normas intelectuais e éticas dos cientistas sofrem os efeitos de "novos imperativos", passando, cada vez mais, a depender das decisões e dos financiamentos externos ao mundo científico. Assim, "as escolhas dos cientistas, que a princípio eram 'livres', tiveram que se dobrar às opções estranhas e ao interesse imanente à Ciência" (JAPIASSU, 1988, p. 146).

Santos e Mortimer (2002) criticam a cientificidade atribuída a produção do conhecimento científico, pois é visto como um conhecimento superior a outras formas de saber, e que por si só todos os problemas são solucionados.

Já Gonçalves (2015, p. 21) cita o determinismo científico na perspectiva de assegurar a Ciência e também a Tecnologia os benefícios e resoluções de problemas da humanidade. Nessa visão o conhecimento científico é sempre verdadeiro, superior e inquestionável.

Sobre a descrição das atividades realizadas por um cientista, L22 relaciona à transmissão do conhecimento: "Desenvolve atividade de pesquisa onde depois de chegar a conclusões de seus experimentos transmite aos seus alunos".

Esta descrição se aproxima da discussão de Educação Bancária, conceituada por Freire (2016) como uma forma de controle na relação educador-educando, em que os conhecimentos são repassados do primeiro para o segundo, de modo que o educando é considerado sujeito passivo, sem consciência. Nessa concepção não há condições de criatividade e autonomia, pois para o autor "ensinar não é transferir conhecimento, mas criar as possibilidades para a sua produção ou a sua construção" (FREIRE, 2013, p. 24).

\section{Imagem reducionista do cientista}

Neste item discutimos as visões dos licenciandos em relação à imagem atribuída a um cientista, tanto física como social. As compreensões dizem respeito a uma imagem eurocêntrica que traduz a ideia de um indivíduo que está apartado da sociedade em geral ou é superior a ela, tendo um estereótipo bem definido, talvez influenciado pela formação escolar, reforçada pelos livros didáticos e mídia social.

Alguns acadêmicos agregaram a visão social de cientista vinculada a uma perspectiva individualista, como um indivíduo sério e "antissocial", a exemplo: "Muito sério, de pouco assunto, meio antissocial" (L3); "Estuda em laboratórios o 
benefício que o experimento trás para a sociedade" (L5); "Trabalha diretamente em laboratórios" (L15); "Antissocial, excluído, deveria interagir com a sociedade" (L7).

É importante que a sociedade tenha clareza de que a Ciência é, acima de tudo, uma produção social, realizada por seres humanos, que reflete os interesses e ideologias de determinadas classes sociais, e que, embora internamente estruturada, apresenta divergências.

Cachapuz et al. (2011) refletindo sobre o estudo e produção da Ciência, mencionam que os fundamentos e métodos, seu crescimento e contexto de descoberta não se constituem uma construção racional isolada, pois faz parte de uma teia de relações, que muitas vezes é ocultada, mas que convém aprofundálas em uma Educação em Ciências. Da mesma forma em que essas concepções distorcidas incidem sobre o ensino praticado e consequentemente na aprendizagem dos estudantes, que seguem uma orientação epistemologicamente pré-concebida.

Os licenciandos ainda associaram a imagem do cientista a uma pessoa antissocial e excluída, que praticamente "vive" em um laboratório. Destacamos o caráter mutável que tanto o fazer científico como o cientista possuem, por este último ser humano, passível a erros, acertos e correlacionado a uma série de fatores que não apenas a produção científica.

Favorável a essa discussão Bueno (2015, p. 39) discorre que "não existiu um método único e universal para chegar a todos os conhecimentos", pois a maior parte dos estudos científicos foram feitos em equipe, as discussões, os debates coletivos, as posições e contraposições foram justamente o que contribuíram para a evolução do conhecimento. $\mathrm{O}$ autor menciona que os programas ou as tradições de investigação desenvolveram-se com os mesmos pressupostos de qualquer atividade humana.

Porém, ainda destaca que as comunidades cientificas foram sempre muito conservadoras, pois aqueles que, de certa forma, afastaram-se da Ciência oficial não foram facilmente aceitos (BUENO, 2015). Diante disso, percebemos que historicamente a Ciência construiu uma imagem de cientista que a tempos é aceita, descrita pelo gênero masculino, magro e que usa óculos, e esse perfil parece sustentar-se até hoje.

Em relação aos aspectos físicos os licenciandos descreveram essa visão clássica de cientista: "Usa óculos, jaleco branco é um pouco doido" (L2); "Masculino, alto, magro, sério e de óculos" (L3).

Segundo Chassot (2003a) a quase ausência de mulheres na História da Ciência, ainda nas primeiras décadas do século XX, estava culturalmente definida como uma carreira imprópria para a mulher, da mesma maneira que, ainda na segunda metade do século $X X$, se dizia quais eram as profissões de homens e quais as de mulheres.

O número de mulheres que se dedicam às Ciências, em termos globais, é ainda menor que o de homens, mesmo que se possa dizer que nas décadas que nos são mais próximas tem havido uma presença significativa das mulheres nas mais diferentes áreas da Ciência, mesmo naquelas que antes pareciam domínio quase exclusivo dos homens (CHASSOT, 2003a; 2003b). Parece que usualmente não se valorizam significativamente as contribuições femininas. 
Fourez (1995, p. 127) esclarece que:

quando se fala de Ciência, pode-se distinguir dois tipos de atitudes. Uma delas chamada de idealista, caracterizada pela aceitação de normas universais e eternas, que determinam de que modo é e como deve ser o real. Uma outra, denominada histórica, vê as configurações assumidas pela Ciência como resultado de uma evolução, que não obedece necessariamente a leis eternas.

Assim, se nos afiliarmos como "históricos" podemos entender que essa concepção de uma Ciência masculina ocorre, como resultado de uma História, humanamente construída, logo falível, e, dessa forma, estaremos sendo agentes desta construção e temos possibilidades de fazer modificações. Ou, se for ao contrário, caso dermos razão àqueles "idealistas" que assumem o conservadorismo de um modelo pronto e imutável, estaremos contribuindo para reforçar preconceitos milenares (CHASSOT, 2003b).

Diante do exposto, as visões que são postas e repassadas em relação ao cientista e as atividades realizadas por este acabam sendo deformadas e empobrecidas, contribuindo para uma imagem pública da Ciência e do cientista como alheia e inatingível, quando não se torna recusável, fazendo também com que o interesse dos jovens seja diminuído drasticamente (CACHAPUZ et al., 2011).

Por isso Cachapuz et al. (2011) argumentam sobre a necessária aposta em uma educação científica para a formação de cidadãos, em detrimento da orientada preparação de futuros cientistas, mesmo com grandes resistências de alguns professores, que defendem que a sociedade necessita de cientistas e tecnólogos, que devem ser selecionados desde cedo.

Vale ressaltar que o discurso de L3 e L22 (respectivamente) em relação ao perfil de um cientista modificou-se ao longo do componente, a saber: "qualquer pessoa"; "uma pessoa com vida social, como outra qualquer". Provavelmente as compreensões destes licenciandos alteraram-se devido as leituras e aprofundamentos teórico-práticos em que foram trabalhos no componente.

\section{ALGUMAS CONSIDERAÇÕES}

Este estudo investigou as compreensões de licenciandos em Ciências da Natureza sobre a NdC e o fazer científico, tanto no aspecto social como físico, no âmbito de um componente curricular sobre experimentação no Ensino de Ciências. Intencionamos discutir essas questões tendo em vista o direcionamento da prática docente, que é influenciado pelas visões atribuídas a concepção de Ciência e da atividade científica.

Quanto à primeira categoria identificamos algumas visões deformadas do trabalho científico: naturalista, salvacionista e utilitarista. Tais compreensões podem ter sido atribuídas pela própria formação escolar e humana dos licenciandos que pode não ter possibilitado o papel da Ciência diante do contexto social e tecnológico.

A partir da segunda categoria percebemos o caráter reducionista atribuído ao perfil do cientista, pois prevaleceram as definições de uma pessoa do gênero 
masculino, que usa óculos e antissocial. Estes discursos descrevem uma visão unitária da Ciência e da produção científica.

É provável que tais visões também direcionem o trabalho desenvolvido pelos licenciandos futuramente em sala de aula e no modo como inserem o papel da experimentação, já que possivelmente os procedimentos adotados estarão assinalados por suas concepções sejam elas acrítica, salvacionista, reducionista ou utilitarista.

Nesse sentido, a extensão das visões deformadas sobre Ciência é resultado de uma ausência, quase absoluta, de uma reflexão epistemológica e também de aceitação acrítica de um ensino pautado por transmissão de conhecimento, sendo necessário uma reflexão crítica sobre tais questões, no intuito de se apropriar com certa facilidade da atividade científica, o que perpassa pensar os objetivos do ensino, enquanto promoção da (re)construção do conhecimento (CACHAPUZ et al., 2011).

Assim, no contexto do componente curricular que também trabalhou essas questões acreditamos que o mesmo possibilitou refletir sobre a concepção da $\mathrm{NdC}$ e do papel do cientista, muitos licenciandos despertaram um olhar mais crítico sobre as atribuições da Ciência, as influências que a mesma possui e como este entendimento é transposto a prática educativa. Pode-se dizer que embora a imagem de um cientista seja fortemente marcada por um perfil eurocêntrico vislumbra-se a inserção de outros sujeitos ao fazer científico, inclusive à possibilidade de serem os próprios licenciandos.

No caso da construção do conhecimento científico, pode-se pensar que a priori não há um roteiro de onde se quer chegar, nem um caminho definitivo para realizar. Nas aulas de Ciências, o professor deve conhecer o produto e o processo que pretende discutir com seus estudantes, e assim, auxiliar nas situações problemas.

Aprender Ciências não é só aprender conceitos. É mais, a aprendizagem conceitual depende da estrutura das concepções, da forma de argumentar, das estratégias de resolução de problemas, da coerência de raciocínio, da utilização das interpretações, e do alcance das intervenções.

Assim sendo, apontamos para a importância da discussão sobre as concepções de Ciências, da NdC e do fazer cientifico para o campo de formação de professores, tanto em caráter inicial como continuado, tendo em vista a relevância de se pensar a discussão sobre aspectos da História e Filosofia da Ciência, desmistificando crenças e aparências à tempos aceitas, para promover definições coerentes com a produção do conhecimento científico. 


\title{
The beliefs and appearances: understanding on science by licensing in natural sciences
}

\begin{abstract}
The present article investigated and discussed the conceptions of graduates of a course in Natural Sciences in relation to the Nature of Science and the profile of the scientist in the scientific making, within the framework of a curricular component of experimentation in science teaching. It is a qualitative research, in which the data were collected through the application of a questionnaire and the construction of a class diary, which contributed to the understanding of the discourse of the research subjects. Through Content Analysis the results were systematized into two categories, of which: deformed vision about the nature of Science and the reductionist image of the scientist. The results pointed to an uncritical understanding of science, guided by a salvationist, reductionist and utilitarian view of scientific work, indicating the need to discuss and rethink the approach to such questions and how they are approached in teacher training.
\end{abstract}

KEYWORDS: Nature of science. Make scientific. Science teaching. 


\section{REFERÊNCIAS}

AULER, D. Interações entre Ciência-Tecnologia-Sociedade no Contexto da Formação de Professores de Ciências. Tese de doutorado em Educação Científica e Tecnológica - Universidade Federal de Santa Catarina, Florianópolis, 2002.

; DELIZOICOV, D. Ciência-Tecnologia-Sociedade: relações estabelecidas por professores de ciências. Revista Electrónica de Enseñanza de Las Ciencias, v. 5, n. 2, 2006. Disponível em:

<http://reec.uvigo.es/volumenes/volumen5/ART8_Vol5_N2.pdf>. Acesso em: 05 nov. 2017.

BACHELARD, G. A formação do espírito científico: contribuições para uma psicanálise do conhecimento. Tradução Estela dos Santos Abreu. Rio de Janeiro: Contraponto, 1996.

BARDIN, L. Análise de Conteúdo. Lisboa, Portugal; Edições 70, LDA, 2009.

BORGES, R. M. R. Em debate: cientificidade e educação em ciências. 2.ed. Porto Alegre: EDIPUCRS, 2007.

BUENO, A. de P. La construcción del conocimiento científico y los contenidos de ciências. In: ALEIXANDRE, M. P. J.; CAAMANÕ, A.; OÑORBE, A.; PEDRINACl, E.; BUENO, A. de P. Enseñar Ciencias. 8ae ed. Barcelona: Gráo, 2015.

CACHAPUZ, A., PRAIA, J., PAIXÃO, F. \& MARTINS, I. Uma visão sobre o ensino das ciências no pós-mudança conceptual: Contributos para a formação de professores. Inovação, 13(2-3), 117-137. 2000.

.; GIL-PEREZ, D.; CARVALHO, A. M. P. de; PRAIA, J.; VILCHES, A. A

necessária renovação do ensino de ciências. 3. ed. São Paulo: Cortez, 2011.

CARVALHO, A. M. P. de. Ensino e aprendizagem de Ciências: referenciais teóricos e dados empíricos das sequências de ensino investigativas - (SEI). In: LONGHINI, Marcos Daniel. (Org.). O uno e o diverso na educação. Uberlândia: EDUFU, 2011. cap. 18. p. $253-266$.

Trabalhar com a formação de professores de ciências: uma experiência encantadora. In: CACHAPUZ, A. F.; CARVALHO, A. M. P. de; GIL-PÉREZ, D. (Orgs.). O Ensino das Ciências como compromisso científico e social: os caminhos que percorremos. São Paulo: Cortez, 2012. 
. A Ciência é masculina? São Leopoldo: Editora Unisinos, 2003b.

Alfabetização Científica: questões e desafios para a educação. 5 ed. ljuí: Unijuí, 2011.

DELIZOICOV, D. Pesquisa em Ensino de Ciências como Ciências Humanas Aplicadas. Caderno Brasileiro de Ensino de Física, Florianópolis - SC, v.21, n.2, p. 145-175, 2004.

;; AULER, D. Ciência, Tecnologia e Formação Social do Espaço: questões sobre a não neutralidade. Alexandria - Revista de Educação em Ciência e Tecnologia, v. 4, n. 2, p. 247-273, 2011.

.; ANGOTTI, J. A.; PERNAMBUCO, M. M. Ensino de Ciências: fundamentos e métodos. 4. ed. São Paulo: Cortez, 2011.

FERREIRA. A. B. H. Novo dicionário Aurélio. 2a ed. São Paulo: Nova Fronteira, 1986.

FONSECA, J. J. S. da. Metodologia da pesquisa científica. Fortaleza: UEC, 2002.

FREIRE, P. Pedagogia da autonomia. Saberes necessários a prática educativa. 46ạ ed. Rio de Janeiro: Paz e Terra, 2013.

Pedagogia do oprimido. 60a ed. Rio de Janeiro: Paz e Terra, 2016.

FREIRE Jr., O. O debate sobre a imagem da ciência a propósito das ideias e da acção de E. P. Wigner. In: SANTOS, B. S. (Ed.), Conhecimento prudente para uma vida decente: Um discurso sobre as ciências. Porto: Edições Afrontamento. 2003.

FOUREZ, G. A construção das Ciências. Introdução à filosofia e a ética das ciências. São Paulo: Editora da Unesp, 1995.

GALLAGHER, J. J. Prospective and practicing secondary school Science teachers' knowledge and beliefs about the philosophy of science. Science Education, 75, 121-133, 1991. imagem não deformada do trabalho científico. Ciência \& Educação, v.7, n.2, p.125-153, 2001. 
GONÇALVES, A. da C. Concepções e ideias de professores de Ciências e Biologia sobre a abordagem CTS no tratamento do tema biodiversidade. ECS, Sinop/MT/Brasil, v. 5, n. 1, p. 19-32, jan./jun. 2015.

HARRES, J. B. S. Concepções de professores sobre a natureza da ciência. Porto Alegre: Curso de Pós-Graduação em Educação - PUC, Tese. Dout. Educação, 1999.

. A natureza da Ciência e implicações para a educação científica. In: MORAES, R. Construtivismo e ensino de ciências: reflexões epistemológicas e metodológicas (Org.). 2. ed. Porto Alegre: EDIPUCRS, 2003.

JAPIASSU, H. Epistemologia Crítica. São Paulo: Letras \& Letras, 1988.

KRASILCHIK, M. O professor e o currículo das ciências. São Paulo: EPU: Editora da Universidade de São Paulo, 1987.

KONDER. O Ensino de Ciências no Brasil: um breve resgate histórico. In: CHASSOT, A. OLIVEIRA, J. R. (Org.). Ciência, ética e cultura na educação. São Leopoldo: Ed. UNISINOS, 1998.

KOSMINSKY, L.; GIORDAN, M. Visões de Ciência e sobre o cientista entre estudantes do Ensino Médio. Química nova na escola, n 15, maio 2002.

LABURÚ, C. E.; ARRUDA, S. de M.; NARDI, R. Os programas de pesquisa de Lakatos: uma leitura para o entendimento da construção do conhecimento em sala de aula em situações de contradição e controvérsia. Ciênc. educ. (Bauru), v. 5, n. 2 Bauru, 1998.

LAURINO, D. P.; PINTO, S. S.; NOVELO, T. P. A concepção de ciência e o espaço do educar. In: HENNING, P. C.; RIBEIRO, P. R. C. (Org.). Diálogos na Educação em Ciências. 1ed. Rio Grande: Editora da FURG, 2013, v. 1, p. 73-81.

LAKATOS, I. O falseamento e a metodologia dos programas de pesquisa. In: LAKATOS, I.; MUSGRAVE, A. (Org.). A crítica e o desenvolvimento do conhecimento. São Paulo: Cultrix, 1979.

LAKATOS, I., MUSGRAVE, A. A crítica e o desenvolvimento do conhecimento. São Paulo : Cultrix, 1979. 
LAKIN, S.; WELLINGTON, J. Who will teach the .nature of science?: teachers views of science and their implications for science education. International Journal of Science Education, 16, 175-190. 1994.

MARCO, B. Alfabetización científica y educación para la ciudadanía. Madrid: Narcea. 1999.

NELKIN, D. Selling science: How the press covers science and technology. New York: W. H. Freeman and Company.1995.

OLIVEIRA, M. B. Neutralidade da ciência, desencantamento do mundo e controle da natureza. Scientiae Studia, v. 6, n. 1, p. 97-116, 2008.

PRAIA, J.; CACHAPUZ, A. Concepções epistemológicas dos professores portugueses sobre o trabalho experimental. Revista Portuguesa de Educação, 11(1), 71-85. 1998.

SANTOS, M. Sociedade e espaço: a formação social como teoria e como método. Boletim Paulista de Geografia, São Paulo: AGB, p. 81-99, 1977.

SANTOS, B. de S. Um discurso sobre as ciências. 4.ed. São Paulo: Cortez, 2006.

SANTOS, W. L. P.; MORTIMER, E. F. Uma análise de pressupostos teóricos da abordagem C-T-S (Ciência-Tecnologia-Sociedade) no contexto da educação brasileira. Ensaio: Pesquisa em Educação em Ciências, v. 2, n. 2, p. 1-23, 2002.

SILVEIRA, R. R. Natureza, Ciência e religião: uma avaliação do naturalismo. Tese. Universidade de Brasília, Programa de Pós-graduação em Filosofia, 2014.

UNIPAMPA, Universidade Federal do Pampa. Projeto Político Pedagógico do Curso de Licenciatura em Ciências da Natureza, 2015.

ZABALZA, M. A. Diários de aula: um instrumento de pesquisa e desenvolvimento profissional. Porto Alegre: Artmed. 2004. 
Recebido: 2017-11-20

Aprovado: 2019-02-27

DOI: $10.3895 /$ rbect.v12n2.7371

Como citar: FONSECA, E. M.; DUSO, L. Entre crenças e aparências: compreensões sobre ciência por licenciandos em ciências da natureza.. Revista Brasileira de Ensino de Ciência e Tecnologia, v. 12, n. 2, 2019. Disponível em:

<https://periodicos.utfpr.edu.br/rbect/article/view/7371>. Acesso em: xxx.

Correspondência: Eril Medeiros da Fonseca - erilmf@gmail.com

Direito autoral: Este artigo está licenciado sob os termos da Licença Creative Commons-Atribuição 4.0 Internacional. 